\title{
THE ROLE OF TAMSULOSIN AND DEFLAZACORT IN THE EXPULSION OF LOWER URETERIC CALCULI
}

\section{Dr. Om Prakash Pawar}

\section{Dr. Asshish*}

\section{MBBS,MS (General Surgery),Sr(General Surgery-skmch, Muzaffarpur.}

Senior Resident, Department of Neurosurgery, CMC Ludhiana. ${ }^{*}$ Corresponding Author

\section{Dr.Ānkita Khurana MBBS, Junior Resident (General Surgery), CMC Ludhiana.}

ABSTRACT BACKGROUND: Urolithiasis stays as the most common ailment witnessed in surgery OPD and emergency. Pharmacological treatment is the primary and cost effective method of the pathology. The use of tamsulosin and deflazacort in the expulsion of the calculi has been studied and analyzed. MATERIAL AND METHODS: A total number of 82 confirmed cases of lower ureteric stone were taken up for the study and randomized division was done into group 1 containing 40 cases who were given analgesic therapy and group 2 containing 42 cases who were given analgesic therapy with tamsulosin and deflazacort . RESULT: from our study, we conclude that the incidence of ureteric calculi is common in the age group of 20-40 years and males when compared to females. the expulsion rate of ureteric calculi in this study series tamsulosin ( $0.4 \mathrm{mg} /$ daily) and deflazacort (30 mg/daily) 31 patients had passed the calculi and 9 patients had no results with a success rate of $77.5 \%$.

\section{KEYWORDS :}

\section{INTRODUCTION}

Urolithiasis is the most common ailment encountered by surgeons and urologists. Spasm of smooth muscles and edema due to stone impaction is the primary cause of presentation. Advances in surgical interventional methods have occurred at the cost of pharmacological treatment. Thus the role of alpha l-adrenergic antagonists and corticosteroids as primary treatment remains questionable.

\section{MATERIALS AND METHODS}

This is a prospective study which was conducted in the Department of Surgery, Darbhanga Medical College \& hospital, Laheriasarai. A total number of 82 confirmed cases of lower ureteric stone were taken up for the study. Randomized division of cases was done into two groups

Group 1 - Patients with ureteral colic who were given diclofenac (50/75 mg) orally/parenterally as needed for pain.

Group 2 - Analgesic therapy plus tamsulosin (0.4 mg/daily) orally and deflazacort(30mg) for 10days

The total duration of the trial was until expulsion of the stone, but no longer than 4 weeks. The patients were then observed weekly and asked for any history of the passage of calculi. The findings were recorded and the patients were monitored and followed up for one month. Stone larger than $10 \mathrm{~mm}$, patients with clinical and laboratory signs of urinary tract infections (UTIs), Severe hydronephrosis, previous history or ureteral manipulation and/or surgery, pregnancy, urethral stricture were excluded from the study.

\section{RESULTS AND ANALYSIS}

The data was collected and analyzed, the results are as follows: The total number of patients included in the study was 82 out of which $25(30 \%)$ of patients in this study group were female patients and $57(70 \%)$ were male patients.

\section{Chart No.1}

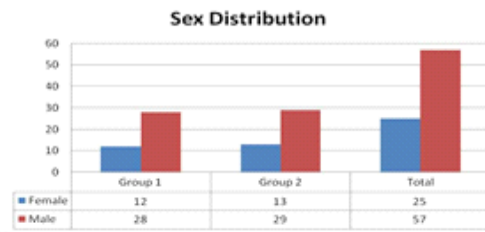

In this series majority of the patients were in the age group of $20-30$ (31 patients) years followed by $30-40$ years ( 22 patients). The mean age group was 36.44 years in females and 38.49 years in males. $37.8 \%$ were in the age group of $20-30$ years, $26.8 \%$ of the patients were in the age group of $30-40$ years, 13.4 $\%$ of patients were in the age group of $40-50$ years, $10.9 \%$ were in the age group of $50-60$ years, $4.8 \%$ were in the age group 60 70 years, $6 \%$ of the patients were between $70-80$ year

Chart No.2

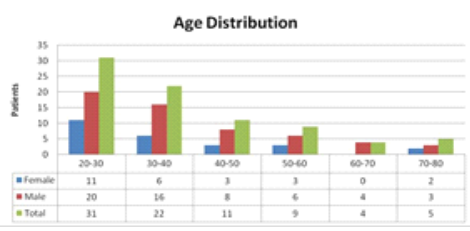

The mean size of the calculus was $6.62 \mathrm{~mm}$ on the right side and $6.07 \mathrm{~mm}$ on the left side.

\section{Chart No.3}

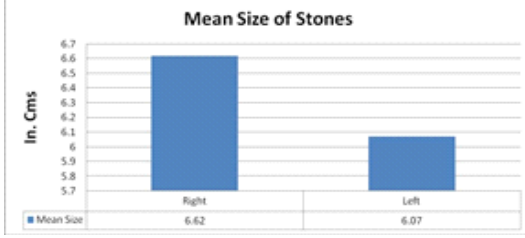

$68 \%$ of the patients complained of only pain abdomen in the loin region, $16 \%$ of the patients had pain abdomen with burning micturition, $10 \%$ patients had associated vomiting with pain abdomen, $5 \%$ patients had hematuria associated with pain abdomen, and $1 \%$ patients had pain abdomen, burning micturition and hematuria.

\section{Chart No.4}

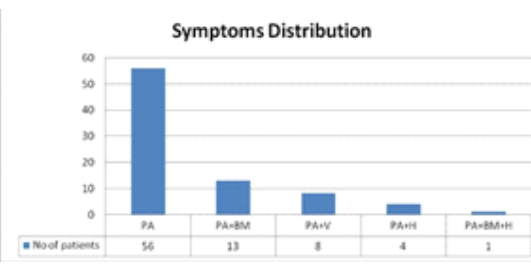


All the patients were tested to detect anaemia. $40 \%$ of the patients had haemoglobin $>13 \mathrm{~g} \% .23 \%$ had hemoglobin in the range of $12-13 \mathrm{~g} \% .17 \%$ of the patients had hemoglobin in the range of $11-12 \mathrm{~g} \% .13 \%$ of the patients had hemoglobin in the range of $10-11 \mathrm{~g} \%$ and $2 \%$ patients had hemoglobin less than $10 \mathrm{~g} \%$.

\section{Chart No.5}

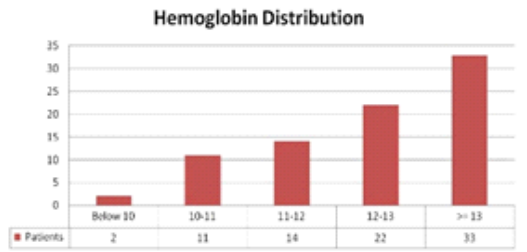

In this series $83 \%$ of the patients had serum creatinine $<1$ $\mathrm{mg} \%$ and $17 \%$ of the patients had serum creatinine $>1 \mathrm{mg} \%$.

\section{Chart No.6}

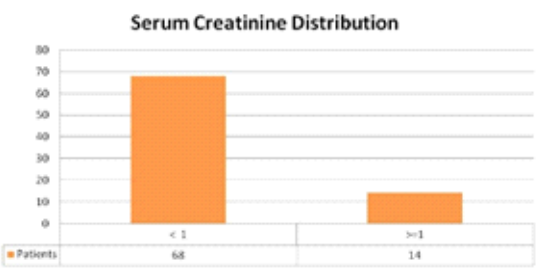

Urine routine results showed presence of Albumin in 12 patients, Pus cells in 18 patients, RBCs in 7 patients and epithelial cells in 24 patients.

\section{Chart No.7}

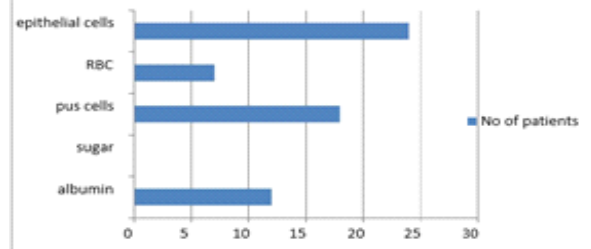

In our study, in the group $1,18 \%$ of patients passed the ureteric calculus within 7 days, $15 \%$ of the patients passed calculus within 14 days, $13 \%$ of the patients passed calculus within 21 days and $32.5 \%$ of the patients passed calculus within 28 days of follow up and $22.5 \%$ patients did not pass calculus. P-value is less than 0.05 , hence statistically significant.

\section{Chart No.8}

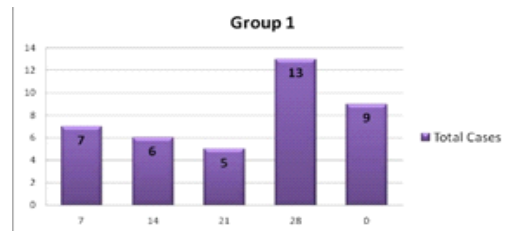

In the second group, $5 \%$ of the patients passed calculus within 7 days, $10 \%$ patients passed calculus within 14 days, $5 \%$ of the patients passed calculus within 21 days and 0 patients passed calculus within 28 days of follow up. $81 \%$ of the patients in the second group did not pass calculus.

\section{Chart No.9}

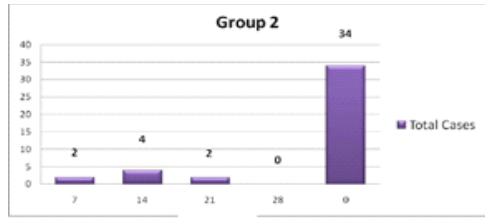

DISCUSSION

A total of 82 patients with particular criteria fixed during the study period were taken and selected by purposive sampling majority of the patients were in the age group of 20-40 years. The mean age group in females was 36.04 and in males was 38.14. The commonest age reported by most of the series for the presentation of ureteric calculi is between $20-40$ years. 1-4. In the first group (in which Drug was given ) $30 \%$ were female patients and $70 \%$ were male patients. In the second group (in which Drug was not given) females were $30 \%$ and male patients were $70 \%$. Most of the studies have reported a male to female ratio between 3:1 and 2:1. In a study by Francesco Porpiglia et al in 2008 reported that in group $A$ the number of males was 17 and females were 29, and in the group, B males were 23 and females were 22.5 In this series the mean size of the calculus was $6.62 \mathrm{~mm}$ on the right side and $6.07 \mathrm{mms}$ on the left side. In a study in 2008 by Francesco Porpiglia et al showed that the mean size of the calculus was $5.93 \mathrm{~mm}$ in group $A$ and $6.03 \mathrm{~mm}$ in group B.3 In the series of symptomology, $10 \%$ of patients came in the first week after the appearance of symptoms, $30 \%$ came in the second week and $60 \%$ patients came in the third and fourth week after the appearance of symptoms. It is reported that duration of symptoms varies from 3 hours to 5 years. $80 \%$ of the patients came within 1 month of onset of symptoms, $4 \%$ gave a history of one year or longer. $100 \%$ ( 82 patients ) had complaints of loin pain, $7.3 \%$ (6 patients) had complaints of vomiting, 4 patients $(4.87 \%)$ had hematuria, 0\% had fever, $12.19 \%$ (10 patients) had complaints of burning micturition. Pain, nausea/ vomiting, hematuria, burning micturition/ urgency/ frequency of micturition and oliguria were the most common symptoms. Morse and Resnick 1991 reported 87\% had loin pain, 17\% patients had vomiting and $3 \%$ presented with fever. 682 patients with distal ureteric calculi, 40 patients were started on alpha 1 blocker drug (Tamsulosin) for 1 month. 42 patients were not given alpha 1 blocker, they were given only NSAIDS and plenty of fluids. Out of the 40 patients who were on alpha 1 blocker tamsulosin ( $0.4 \mathrm{mg} /$ daily) and deflazacort (30mg/daily) 31 patients had passed the calculi and 9 patients had no results with a success rate of $77.5 \%$. In the 42 patients who were not on Tamsulosin and deflazacort, 8 patients passed the calculi and 34 patients did not pass the calculi. 9 patients among the 42 underwent ureterorenoscopy (URS). The success rate for such ureteroscopic management of lower ureteric calculus is $95 \%$ to $100 \%$ and for calculi in middle $1 / 3$ rd and lower $1 / 3$ rd of the ureter, the success rate is $44 \%$ to $95 \%$. In most of the reported series, there remain, from $1-10 \%$ of patients who require open removal of their calculi.

\section{CONCLUSION}

Thus from our study, we conclude that the incidence of ureteric calculi is common in the age group of $20-40$ years and males when compared to females. the expulsion rate of ureteric calculi in this study series tamsulosin $(0.4 \mathrm{mg} /$ daily $)$ and deflazacort ( $30 \mathrm{mg} /$ daily) 31 patients had passed the calculi and 9 patients had no results with a success rate of $77.5 \%$. Main symptoms of presentation are loin pain in $100 \%$ of patients, burning micturition in $12.19 \%$ patient. USG is a very sensitive and specific investigation for diagnosis. The common complications observed with tamsulosin are headache, diarrhoea and abnormal ejaculation like retrograde ejaculation. The most common side effects of steroids include weight gain, nausea, mood changes, excessive hair growth and development of acne.

\section{References:}

1. Sutton and Walker, 1980. Sutton RA, Walker VR: Responses to hydrochlorothiazide and acetazolamide in patients with calcium stones: Evidence suggesting a defect in renal tubular function. N Engl J Med 1980; 302:709-713

2. Morse RM, Resnick MI. Ureteral calculi: Natural history and treatment in the era of advanced technology. J Urol 1991;145:263-5, and Glowacki LS, Beecroft ML, Cook RJ, Pahl D, Churchill DN. The natural history of asymptomatic urolithiasis. J Urol 1992;147:319-21 
3. Ehreth JT, Drach GW, Arnett ML, et al. Extracorporeal shock wave lithotripsy: Multicenter study of kidney and upper ureter versus middle and lower ureter treatments. J Urol 1994; 152: 1379-85.

4. Tawfiek ER, Bagley DH. Management of upper urinary tract calculi with ureteroscopic techniques. Urology 1999; 53:25-31.

5. Porpiglia F, Ghignone G et al. Nifedepine versus tamsulosin for the management of lower ureteral stones. J urol 2004; 172: 568-71.

6. Reid M. Morse, Martin I. Resnick,Ureteral Calculi: Natural History and Treatment in an Era of Advanced Technology, The Journal of Urology, Volume 145 , Issue 